\title{
Multicriteria analysis model for urban open space renovation: An application for Rome
}

\author{
Letizia Martinelli ${ }^{\mathrm{a}, \mathrm{b}, *}$, Alessandra Battisti $^{\mathrm{a}}$, Andreas Matzarakis $^{\mathrm{b}}$ \\ a Department of Planning, Design and Technology of Architecture, Sapienza University, Via Flaminia 72, 00196 Rome, Italy \\ ${ }^{\mathrm{b}}$ Chair for Meteorology and Climatology, Albert-Ludwigs University Freiburg, Werthmannstr. 10, D-79085 Freiburg, Germany
}

\section{A R T I C L E I N F O}

\section{Article history:}

Available online 11 July 2014

\section{Keywords:}

Multicriteria analysis

Public open space

Public decision process

\begin{abstract}
A B S T R A C T
Urban public open space has continuously played a significant role in enhancing the quality of life of urban inhabitants and in supporting urban metabolism. However, open space has experienced a physical and social decline, while its heterogeneity and richness is often neglected and its contribution to the wellbeing of a community ignored within current planning instruments. Therefore, the aim of the research presented in this study is to develop a multicriteria analysis (MCA) method to support the decision process of open space renovation and the selection of a renovation scenario. The method is based on the Analytic Hierarchy Process (AHP) and adapts existing models and criteria to the investigation field. It is applied by means of a computer-based tool, which permits an ex-ante evaluation of alternative projects, rating them against several weighted objectives using a set of indicators, thus combining the common design practice of scenario planning with a multicriteria analysis. In order to clarify the tool operation, this article illustrates its application to a theoretical case, which represents a conceivable public open space renovation in a simplified way. The choice of a theoretical case, instead of an actual one, permits us to follow the process without referring to a specific situation, in order to have a general overview of the MCA method's implementation.
\end{abstract}

(C) 2014 Elsevier Ltd. All rights reserved.

\section{Introduction}

\subsection{Urban open space renovation}

Urban public open spaces comprise of all parts of the physical environment that the public can experience or have access to (Lofland, 1998). Open areas have continuously performed a fundamental social and cultural function, especially in the countries where benign climatic conditions favour an extended season for outdoor activities (Commission for Architecture and the Built Environment \& Greater London Authority, 2008). Even within a wide variation of typology, morphology and use, the system of spaces "between" buildings still provides a framework for several activities, planned or spontaneous (Gehl, 1980), thus contributing to the quality of life of the urban inhabitants, as well as to the increased social cohesion and the feeling of

* Corresponding author at: Department of Planning, Design and Technology of Architecture, Sapienza University, Via Flaminia 72, 00196 Rome, Italy. Tel.: +49 7612036925; fax: +49 7612036922.

E-mail addresses: letizia.martinelli@uniroma1.it, letizia.martinelli@gmail.com (L. Martinelli). identity and security (Whyte, 1980). It also represents an essential part of the towns' aesthetic and plays a significant role in urban metabolism (Chrysoulakis, 2008). In fact, properly designed open spaces can promote vegetation integration within cities (GFA Consulting, 1996); can sustain the urban hydrological cycle by providing temporary storage for rainwater, enhancing water drainage and depuration for non-potable uses and supporting controlled infiltration (Makropoulos, Natsis, Liu, Mittas, \& Butler, 2008; Niemczynowicz, 1999); can substantially affect the urban microclimate (Givoni, 1998); can help reduce energy and resource consumption (Futcher, Kershaw, \& Mills, 2013).

Nevertheless, the value of open space, is experiencing a physical decline, while the heterogeneity and richness of public life is often neglected and its contribution to the well-being of a community ignored (Carmona, 2010). City planning based entirely on zoning techniques has generated the illusion of addressing the standard needs of a standard individual, regardless of local tradition or lifestyle, within an extremely simplified urban structure that can accommodate only strictly separated functions (Rykwert, 2000). Political and socioeconomic issues, such as public authority weakening, indoor displacement of numerous urban functions (Sennett, 1977) and emphasis on private transportation (Newman \& Kenworthy, 1999) have downgraded urban open space to a 
leftover expanse with no defined purpose, mostly used as a car park, thus increasingly deteriorating over time. The phenomenon has been further intensified by urban sprawl, which dissolves and fragments open space (European Environment Agency (EEA), 2005b). Moreover, this lack of interest has led to underestimate open space function as a microclimate modifier, though it has been acknowledged (Givoni, 1998) that urban fabric affects climatic elements, such as solar radiation and heat distribution, air temperature, air humidity and wind conditions.

However, there is rising recognition of communal open space importance in assuring the social and environmental quality of towns (Carmona \& Tiesdell, 2007). Urban renovation represents one of the European Union's main strategies towards sustainable cities and has stressed the necessity to tackle urban open space renewal, in order to intensify its use and thus indirectly influence the economic and ecological behaviour of the urban ecosystem as a whole (European Commission, 1991). To achieve these targets, public open space renovation and management must deal with two fundamental issues. On the one hand, they have to improve the rational use of resources in the whole life-cycle of an urban space and its components (such as equipment and outdoor furniture), from material production, to construction, maintenance and possible disposal. On the other hand, they have to ameliorate the multi-sensory comfort of the users, addressing use and aesthetic qualities, safety and air quality, and paying special attention towards bioclimatic comfort (Matzarakis, Mayer, \& Iziomon, 1999).

This full range of interdisciplinary goals, which involve heterogeneous actors and stakeholders within a complex system, requires an integrated and flexible approach that can incorporate existing values and adjust to changing conditions (Böhner, 2006). This approach justifies micro-scale interventions in a delimited area, which allow the decision process to deal readily with diverse topics and to evolve over time according to feedback, within the framework of broader planning policy (European Ministers on Urban Development, 2010).

To achieve this result, however, the decision makers need to employ specific techniques that can support this process, alongside current planning instruments, to enhance quality outcomes. To address this shortcoming in planning policy, this study aims to develop a multicriteria analysis tool that applies to the decision process of public open space renovation. In fact, a multicriteria analysis appears particularly consistent with open space renovation issues, as it is capable of taking into account multiple subjects in a structured way, highlighting matters of judgement, coordinating development and responding to change.

\subsection{Multicriteria analysis for urban design}

Multicriteria analysis (MCA) is a mathematical tool designed to investigate a number of possible alternatives for a given question against several, often conflicting, priorities (Voogd, 1983), providing a structured method for comparative analysis. It thus helps the decision makers investigate complex problems with quali-quantitative attributes, using open and explicit judgement criteria to obtain better informed and justifiable choices (Goodwin \& Wright, 1991). When dealing with composite, unpredictable issues, MCA possesses various advantages over informal judgement unsupported by analysis. The process of analysing the decision adheres to established techniques and is well documented; therefore, it can be cross-referenced with other information sources, amended or improved and reproduced for similar decisions. This process also provides an important means of communication between the decision makers and the wider community, creating a shared understanding about the issues at hand.

One of the crucial points of MCA is the prominence given to the decision makers' judgement regarding the problem to address.
In fact, rather than being an "objective" method such as costeffectiveness analysis (Great Britain \& Treasury, 2003), MCA has the purpose of providing structure and openness to subjective opinion. The method is generally used to rank proposed alternatives against each of the priorities that are defined and weighted by decision makers, thus presenting them a broader understanding of the situation. It can also allow the identification of a single most fitting solution for a certain set of priorities. In any case, it usually has an advisory function rather than mandatory: the responsibility to provide a unique answer belongs to the decision makers and is necessarily a human function (Department for Communities \& Local Government, 2009).

MCA has been widely employed in urban planning, especially within cities (Curwell, 2005a), in order to promote a common view of the strategic goals of urban development and to address environmental, social and economic aspects of sustainability. Conversely, at a neighbourhood and building level, environmental certifications represent a standardised version on MCA, with a fixed process and given objectives and criteria, with the purpose of establishing quality benchmarks for the building stock (Lee, 2012).

\subsection{Multicriteria analysis for public urban open space renovation}

Compared with existing MCA approaches on different spatial levels and different topics, public open space renovation demonstrates some singularity. Urban open space possesses a relevant hybrid character (Tibbalds, 1992), as it hosts heterogeneous and often informal functions, while it is difficult to track down its stakeholders and to accurately define their necessities. Besides, it is hard to isolate its metabolism from the entire urban ecosystem. At the same time, public intervention on a small-medium scale requires decision support methods that are economic, fast, easy to use and easy to monitor, yet still grant public authorities considerable control over their choices.

For these reasons, the study proposes a flexible, but partly set up MCA model, where assessment criteria are established in advance. This approach can appear incoherent with MCA's ability to represent a particular situation and the corresponding decision makers' preferences very specifically. However, such a model can be generally operable, providing the decision makers with a sound starting point for discussion, and yet adapt to specific urban context and encompass the stakeholders' viewpoints and objectives. Moreover, it stresses the relevance of sustainability targets for urban planning and it consents us to compare and analyse different renovation scenarios for open spaces, thus giving an overview of current practice.

To increase consistency for the proposed set up approach, the MCA model should apply to a selected typology of urban open spaces, with similar morphological, social and microclimatic features that solicit similar renovation strategies towards sustainability. In the present case, the interest focuses on public spaces with a distinct morphology and a legible shape, whom Christoper Alexander (Alexander, Ishikawa, \& Silverstein, 1977) defined "positive spaces". Therefore, the selected criteria used to define this typology are the floor area ratio of the surroundings and the linear dimension and height/width ratio of the open space itself. Employing these criteria, small scale squares or streets (linear dimension of the shortest side less than $100 \mathrm{~m}, \mathrm{~h} / \mathrm{w}$ ratio calculated on the shortest side more than 0.2 ), located in a medium-high compact urban fabric (floor area ratio in a radius of $250 \mathrm{~m}$ from the centre of the open space more than $40 \%$ ), at least partly pedestrian, are considered. Moreover, these open spaces should be located within Mediterranean climatic zone (Kottek, Grieser, Beck, Rudolf, \& Rubel, 2006) in the Mediterranean basin.

Nevertheless, decision makers or researchers can integrate the given list of criteria with additional records, or even significantly transform it. Besides, the focal point of the study resides in the 


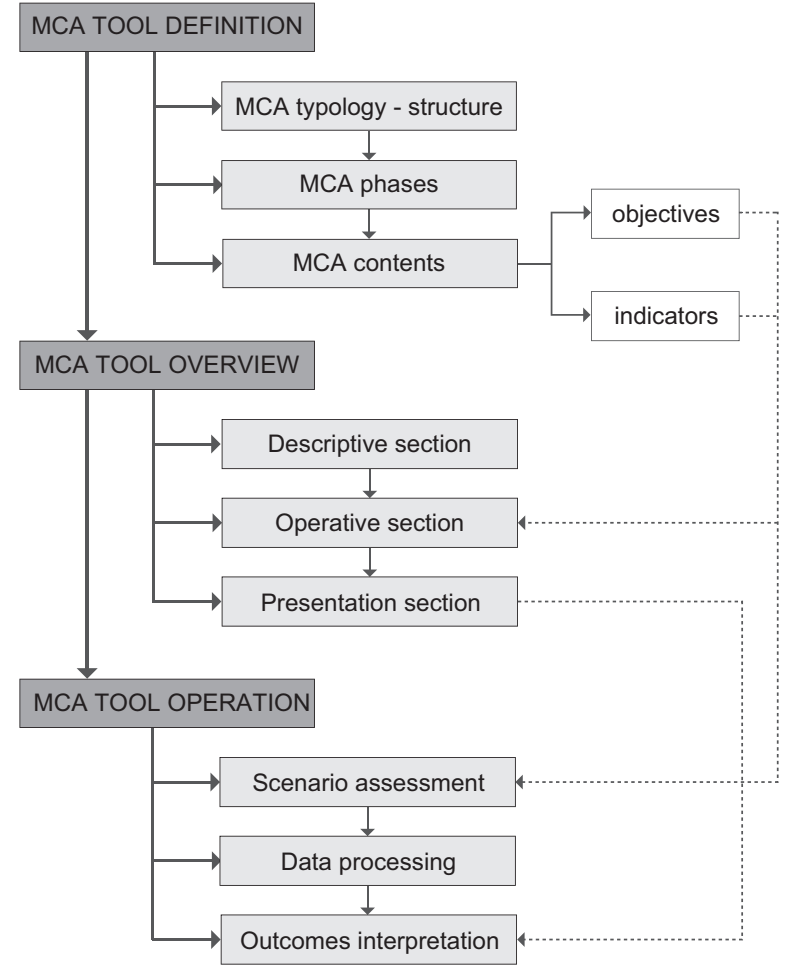

Fig. 1. General structure of the study.

analysis of MCA feasibility for public open space renovation: the focus is more on the MCA model structure rather than on specific contents. In fact, MCA model flexibility can adjust to different open space typologies, such as parks or waterfronts, or can take into account different points of view, such as psychological or sociological approaches.

The MCA model presented provides an operative tool to help decision-makers estimate the existing conditions of open space and assist the choice of a renovation scenario, in the frame of existing mandatory planning instruments. It permits an ex-ante evaluation of alternative projects, rating them against several weighted objects using a set of indicators, thus combining the common design practice of scenario planning with MCA (Montibeller, Gummer, \& Tumidei, 2006). Decision modelling of each scenario helps to present its main features in a structured manner, rendering the comparison between scenarios more consistent and avoiding the oversight of some critical concerns (Stewart, French, \& Rios, 2013).

In order to develop the model, this study has defined its structure and contents, based on existing methods and criteria. Afterwards, the model has been integrated into a computer-based tool to support the decision-making process. To validate and demonstrate its operation, the study has eventually applied the model to a theoretical case, which represents a conceivable public open space renovation in a simplified way (Fig. 1).

\section{Methodology}

\subsection{MCA model's typology definition}

The study has carried out an inquiry over MCA procedures principally oriented towards urban planning, to select the best model to support the decision process of open space renovation, as shown

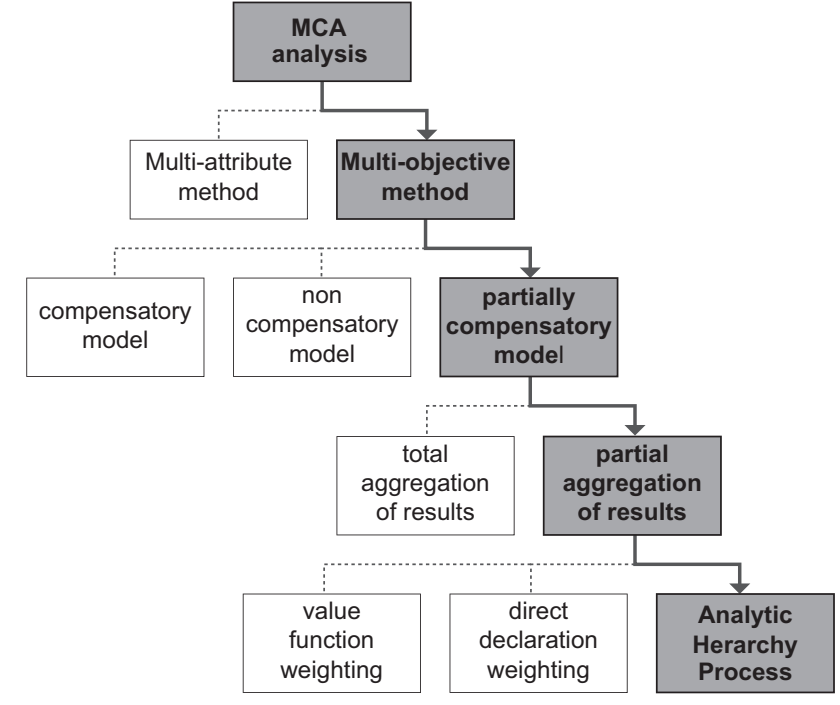

Fig. 2. Selection of the MCA method suitable for public open space renovation.

in Fig. 2. The survey concentrates on the models that adhere best to the study field and that meet the following criteria:

1. transparency

2. flexibility

3. ease of use

4. realistic time and work force requirements

5. viable integration into existing planning instruments

6. relevance of the decision makers' autonomy and judgement.

The initial consideration in the choice of MCA technique is the number of alternatives to appraise. Multi-objective methods are used when alternatives are not predetermined; instead, a set of objective functions is optimised subject to a set of constraints, in order to build the best alternative (Steuer, 1986). On the other hand, multi-attribute methods evaluate a discrete number of alternatives against several objectives; the best alternative is usually selected by making comparisons between options with respect to each objective. In the assumed open space renovation process, the decision stage, which is performed by public bodies and stakeholders, and the scenarios' definition stage, which is accomplished by designers, are separated (Cliímaco, 1997). The MCA model concerns the decision stage and supports the evaluation of given scenarios, which are limited in number. Therefore, the multi-attribute method is considered to be the best option. However, differently from common multi-attribute approaches (Hwang \& Yoon, 1981; Tzeng \& Huang, 2011), objectives are specified prior to the scenarios' definition phase, in order to encourage consistent scenario processing.

In the multiple-attribute method, decision makers select a group of quantifiable or non-quantifiable objectives and establish indicators to assess the alternatives' compliance with each objective. The central element of this method is the performance matrix, where each column presents a possible alternative or scenario planning and each row describes the alternative score against each evaluation indicator, thus indirectly conveying its performance with regards to the objectives. Objectives are usually conflicting; therefore, the results are highly dependent on the preferences of the decision makers and the possible compromises between objectives. The proposed MCA model is compensatory in nature and allows trade-offs between criteria, in order to enhance discussion and agreement among the decision makers. Consequently, good performance on one criterion can in principle compensate for a weaker performance on another (Keeney, 1982). 
Where compensation is acceptable, most MCA methods involve implicit or explicit aggregation of each option's performance across the criteria to formulate an overall assessment (Schärlig, 1985). However, it is fairly difficult to define a utility function that represents all the possible consequences of an urban renovation scenario; moreover, the scope of MCA within the present study is to organise the decision process and to support alternative evaluations, but not to impose a single solution. Therefore, the MCA model partially aggregates criteria, even if a total aggregation can be performed at request of the decision makers.

In order to emphasise the decision makers' preferences, the MCA model adopted utilises weights. Weight is a numeric amount assigned to an evaluation criterion, which represents its importance relative to the other criteria. The bigger the weight, the more important a given criterion is (Choo, Schoner, \& Wedley, 1999; Greening \& Bernow, 2004; Hobbs \& Meier, 2000). Weights are defined according to the Analytic Hierarchy Process (AHP) developed by Saaty (1980) and broadly used in urban planning (Pohekar \& Ramachandran, 2004). This process arranges a complex question into a hierarchy of objectives, sub-objectives and indicators known as "value tree". At each level of the hierarchy, the elements are compared in pairs to evaluate their relative importance against the correspondent element in the above level. Hence, the process provides a clear framework of the decision makers' priorities and clarifies the elements' contribution to the result.

Within AHP, assessment indicators are normalised on a standard interval scale, in order to simplify the comparison of the results and allow for weighting. The selected MCA model calculates normalised scores by comparing the indicator score for each alternative to a benchmark, which represents a "business as usual" situation (Bell, Hobbs, Elliott, Ellis, \& Robinson, 2001; González, Donnelly, Jones, Chrysoulakis, \& Lopes, 2013), and then ranks the normalised scores on a standard scale. The benchmark can refer to legislation, where available; otherwise, it refers to existing conditions. For qualitative indicators, the model uses direct ranking, which relies on the judgement of one or more experts, in order to associate a standard scale number to each alternative. In this case, normalisation is not required.

\subsection{MCA model phases}

The MCA model defined provides a framework for the selection of a urban open space renovation scenario. Hence, in order to apply the model, the study proposes to divide the decision process into operative phases (Fig. 3):

1. identify the problem to address, thus selecting and analysing the space to be renovated

2. establish renovation objectives

3. define indicators to assess the achievement of objectives

4. weight indicators and objectives

5. develop open space renovation scenarios

6. evaluate each scenario against the indicators

7. normalise and partially (or totally) aggregate the results

8. present the results

9. select a scenario.

\subsection{MCA criteria definition}

The definition process of the objectives and indicators is based on sustainability principles (Gibson, 2005; Morrison-Saunders \& Therivel, 2006) and adopts the following criteria:

1. number limitation

2. comprehensibility and adaptability to public decision procedures
3. consistency with public open space renovation

4. suitability for ex-ante evaluation

5. prevalence of performance approach over prescriptive approach.

It has required the analysis and classification of several theoretical and operational sources, selected for their conformity to the investigation topic and to MCA methodology. The sources comprehend Decision Support Systems for urban planning (Böhner, 2006; González et al., 2013; Matthies, Giupponi, \& Ostendorf, 2007), guidelines and best practices for open space design (Centre for Renewable Energy Sources (Pikermi). Department of Buildings, 2004; Department of the Environment, Transport and the Regions \& Commission for Architecture and the Built Environment, 2000; Homes \& Community Agency, 2000), environmental certification on a city and neighbourhood scale (Curwell, 2005b): this broader investigation ensures that the proposed model links directly with existing planning policy and practice on different scales.

\subsubsection{Objectives definition}

Objectives express the decision makers' goals on an operative level. They do not represent vague aspirations, but concrete achievements that communities and public bodies can reach when supplied with allocated resources in a given time-horizon. The acronym S.M.A.R.T., commonly used in urban planning (Hewitt, 1995), synthesises their attributes well; in fact, it indicates that objectives should be: specific to a defined area of improvement; measurable, thus quantifying progress; agreed among the decision makers; realistic to achieve given available resources; time-dependent to a feasible time horizon.

Since the MCA model assesses renovation projects and not monitoring, objectives focus on the design and construction phases. They are organised in a hierarchical tree with two levels: general and specific objectives.

General objectives occupy the top level and constitute guide principles for action. In this study, they are represented by the three canonical sustainable categories (Gibson, 2005; Lehtonen, 2004; Roseland, 2000): environmental, social and economic sustainability.

Specific objectives are situated on the base level and emphasise definite tasks. Specific objectives of environmental sustainability particularly concern the management of energy, water, materials and waste resources. They refer to two complementary actions: the maximisation of the existing resources' efficiency; the minimisation of the resources' consumption. Specific objectives of economic sustainability deal with project feasibility during construction and use. Specific objectives of social sustainability take into account human bioclimatic comfort conditions and open space functions. At present, the proposed objective list discards symbolic values, which express the space potential to convey cultural identity and social cohesion for the users and the broader community and which depend on the development of the space over time; therefore, they are particularly complex to address in an ex-ante evaluation.

\subsubsection{Indicators definition}

Objectives express the decision makers' will to achieve a target; indicators permit us to evaluate the fulfilment of each objective, assessing and comparing the impact of several alternatives against a standard ranking scale. Indicators are defined as the parameters able to provide information on a phenomenon's conditions or on a phenomenon's trajectory (Adriaanse, 1993). They synthetically represent the attributes of a given situation, making qualitative and quantitative changes easy to communicate. In order to attain a high level of effectiveness, numerous guidelines (Curwell, 2005a; Donnelly, Jones, O'Mahony, \& Byrne, 2007; Gabrielsen \& Bosch, 2003) recommend the use of indicators that possess the following characteristics: 


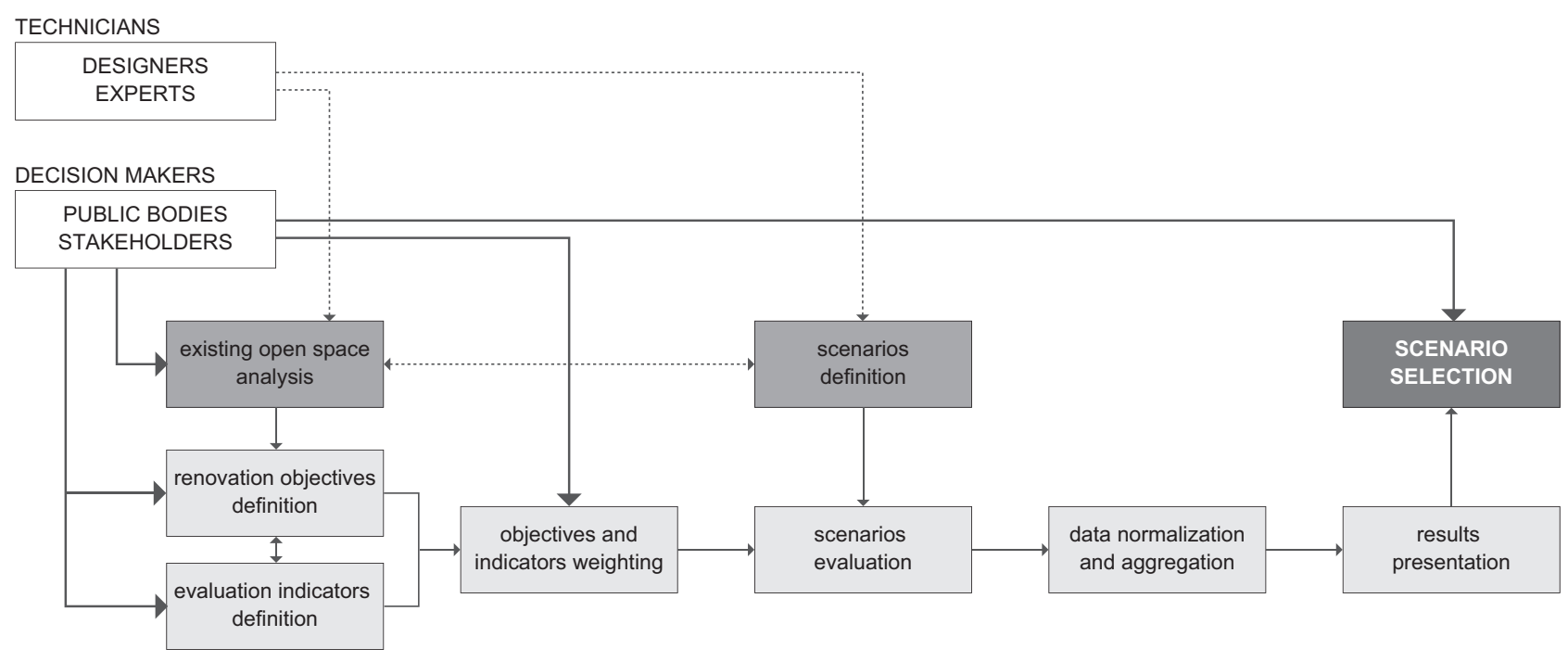

Fig. 3. Decision process of open space renovation, according to the defined MCA model.

1. significance, giving a sound image of the issues being considered and showing changes displaying an appropriate level of detail

2. ease of measure within a sound, scientific base and reproducible method

3. ease of interpretation for non-experts, such as public bodies, stakeholders or public opinion

4. orientation towards action, describing phenomena that can be directly influenced by human intervention.

In order to address complex ecosystems interaction, the proposed MCA model requires a set of integrated indicators, which represent a given number of public open space exemplar features in a simplified way. This set of indicators should be complete, nonredundant and coherent, so that the decision makers' preferences at different levels are consistent.

Within the proposed model, the selection of the indicators depends on the objectives to be evaluated and the expected accessibility of sound datasets. The aim of the evaluation process is to analyse the environmental, social and economic characteristics of renovation scenarios, hence the emphasis is on ex-ante assessment rather than on monitoring. Moreover, the selection of the indicators refers to the OECD Pressure-State-Response framework (Organisation for Economic Co-operation and Development (OECD), 1993), which promotes the distinction between the causes (pressures) of a given situation, their effects on the state of the environment and the correspondent social response.

The indicators used are mostly performance indicators (European Environment Agency (EEA), 2005a), which are connected with target values and measure the distance between the current situation and a desired situation. They are also specific, as they explicitly examine a given typology of public open space, and essential, as they qualify as the smallest number possible to be representative (Organisation for Economic Co-operation and Development (OECD), 2003). The MCA model thoroughly describes quantitative indicators measured with direct or indirect measurements or model simulations, while indicators that concern matters of judgement are only briefly presented. Therefore, decision makers can autonomously adapt qualitative issues to the specific situation.

The study classifies and organises indicators according to the objective they evaluate. In order to consent AHP weighting, the relationship between the indicators and the objectives must be univocal: each indicator refers to a single objective; each objective comprehends at least one indicator. In line with AHP, the indicators' scores are normalised on a standard scale from 0 to 1 , by comparing the score of each alternative to the score of a given benchmark.

Environmental indicators, like environmental objectives, deal with the rational use of energy and resources, which are calculated with direct and indirect measurements, and are associated with European policy on natural capital conservation (European Commission, 1999). Economic indicators refer to the project's costs and maintenance optimisation; this last indicator relies on the judgement of experts. Social indicators deal with two issues: human bioclimatic comfort parameters, which depict people thermo-physiological well-being and are analysed through model simulations; use parameters, which represents the degree to which the form and equipment of the spaces match people existing and (possible) future activities. As this capability of the space is related on its specific functions within the city, the associated indicator is evaluated by means of expert judgement, according to criteria locally defined by the stakeholders.

The complete hierarchical tree of objectives and indicators is provided in Fig. 4.

Among these indicators, bioclimatic comfort can play a significant role in connecting environmental and social issues. For this reason, the MCA model utilises the Physiologically Equivalent Temperature (PET) index to analyse microclimate (Höppe, 1993), as this index is reliable to take into account users' physiological and psychological well-being and is able to show the relationship between urban morphology and microclimate (Fröhlich \& Matzarakis, 2013). Moreover, it is also relatively easy to measure on forthcoming scenarios using software simulation, and its measurement unit $\left({ }^{\circ} \mathrm{C}\right)$ makes results more comprehensible for urban planners or decision makers, who are not so familiar with modern humanbiometeorological terminology (Matzarakis et al., 1999).

PET calculation usually evaluates PET evolution in space or time. On the contrary, MCA calculation requires a single rank for each indicator, in order to normalise and aggregate the results. For this reason, the study establishes three indicators based on PET, which evaluate mean comfort conditions throughout the area and optimised comfort conditions for particular points or for selected activities.

The MCA model applies to specific public bodies' decisions, within existing planning instruments, and it has the prime scope to organise and assist the stakeholders' judgement. Therefore, it provides no mandatory benchmark. However, as environmental indicators represent a critical topic towards sustainability, the model proposes to define environmental benchmarks according to 


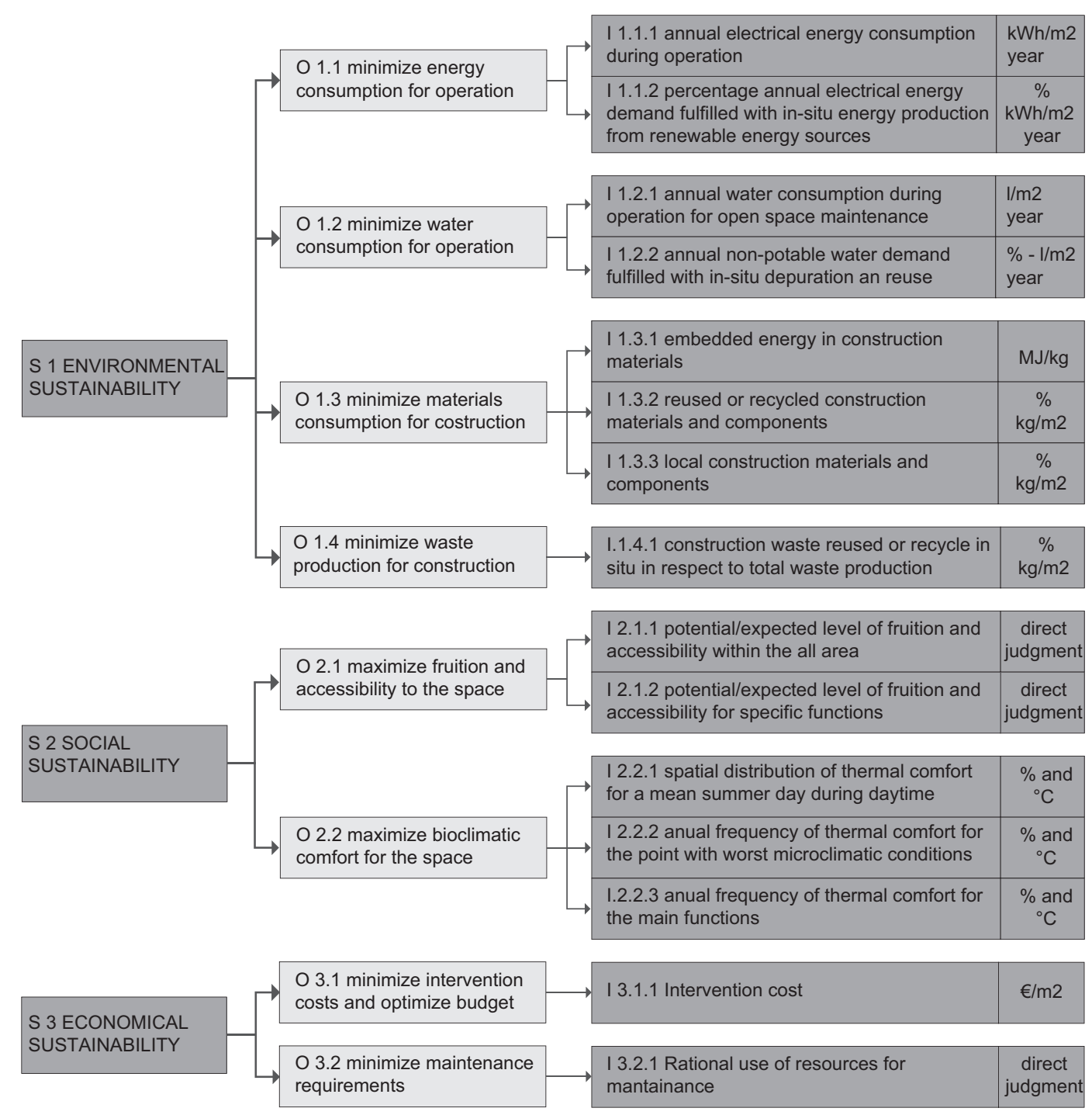

Fig. 4. Objectives and indicators hierarchical tree.

local legislation, considered as the "business as usual" situation; thus, improvements from legislation requirements will be encouraged. If no local legislation exists, the decision makers should refer to existing national or international guidelines (for example, the requirements of Environmental Certifications that are applied in the given country). Otherwise, benchmarks can derive from public open space conditions prior to renovation, in order to underline the scenarios' improvements on existing conditions; this last recommendation can generally be employed with social and economical indicators. Weights are not suggested, as MCA method emphasizes the preferences of the decision makers; nevertheless, it is strongly recommended to consider the significance of environmental objectives and indicators during weighting phase.

\section{Results and case study}

\subsection{MCA tool presentation}

The proposed MCA model is implemented by means of a computer-based spreadsheet tool, which includes criteria illustration, weighting, the normalisation of the results and their presentation phases; instead, the definition of the scenarios' phase and the evaluation of the indicators' phase are external. The model's application is voluntary and does not substitute the required planning instrument; rather it represents a complementary tool. The model's scope is to enable public bodies to choose a project for urban open space renovation, assuming that the appointed designers provide more than one option. Moreover, if the planning instrument entails a design competition, decision makers can use the method to select a single winner project.

The spreadsheet consists of three sections: the first being descriptive in nature, the second operative and the third a presentation.

The descriptive section explains the MCA method and the indicators' calculation and contains the hierarchical tree of objectives and indicators. This list is flexible and can be adjusted in line with the decision makers' motivations: objectives can be added or removed, ensuring that new objectives link to new indicators and that they adapt to the existing procedure.

Within the operative section, decision makers or appointed experts enter input data for MCA. This data includes the indicators' benchmarks, objectives and indicators' weight and score for each scenario.

The presentation section returns MCA evaluation outputs. An evaluation matrix ranks the scenarios according to their normalised and weighted results; moreover, several graphs simplify the understanding of the results. 


\subsection{MCA tool operation}

If a public body decides to utilise the tool in order to support the choice of a renovation scenario for a certain urban open space, it firstly has to analyse the morphology and use of the space alongside its social and environmental characteristics. This phase promotes the MCA model's adaptation to the specific situation, since decision makers have the possibility to specify the elements of the MCA model that have been deliberately undetermined by the study, such as qualitative criteria and the indicators' benchmarks. They can also add or remove objects or indicators from the spreadsheet.

Then, within the criteria value tree, the decision makers perform pairwise comparisons of the indicators and objectives, to express the relative importance of each element on a hierarchical scale with respect to the element at the higher level. Thus, the program calculates each element's weight and produces a framework of the decision makers' shared preferences. This phase permits us to incorporate subjective opinions into the analysis process, modifying the results to suit the vision of a specific group. This is particularly relevant when a broader set of stakeholders is involved in the decision through participation techniques. For a detailed description of pairwise comparison calculation within the AHP model, please refer to (Saaty, 1980).

As indicated above, scenario definition is an external phase. Decision makers establish the requirements for this step, according to the planning instrument in use whilst following the MCA tool indications. During this phase, appointed designers or competitors in a design competition prepare different renovation projects. Afterwards, the same designers or appointed experts evaluate each scenario against the settled indicators, using the calculation established by the MCA tool. Assessment comprehends indirect measurements, previsions and judgements.

After the assessment, the ranks of all the indicators for each scenario are inserted into the spreadsheet. The program then normalises the data and weights them according to the decision makers' preferences. Partial data aggregation is performed according to Cobb-Douglas function (Cobb \& Douglas, 1928). The program aggregates indicators and specific objectives, but, even if it is technically possible, it normally does not aggregate general objectives.

Then, the program presents the assessment results of the indicators in a systematic manner, by means of an evaluation matrix and various bar graphs and radar chart, in order to allow for an accurate and clear comparison between scenarios. The matrix gives coherent and sharp structure to a quali-quantitative analysis and emphasises the relationship between environmental, social and economic aspects of open space renovation.

Finally, the decision makers select a renovation scenario. However, MCA results are no mandatory: the evaluation matrix should support and inform the discussion amongst the decision makers and help them to find a compromise, but the ultimate decision represents a synthetic and autonomous resolution of the public body and involved stakeholders. The MCA tool's operation process is exemplified in Fig. 5.

\subsection{Application of the MCA tool to a theoretical case}

In order to clarify its operation the proposed MCA model has been applied to a theoretical case, which represents a conceivable public open space renovation in a simplified way. The choice of a theoretical case, instead of an actual one, permits us to follow the process without references to a specific situation, in order to have a general overview of the MCA method's implementation. Moreover, within an abstract situation, it is possible to ostensibly present the MCA tool phases that require a multidisciplinary approach, such as indicator assessment, or that involve several stakeholders, such as the weighting phase. For these reasons, fictitious, but compatible

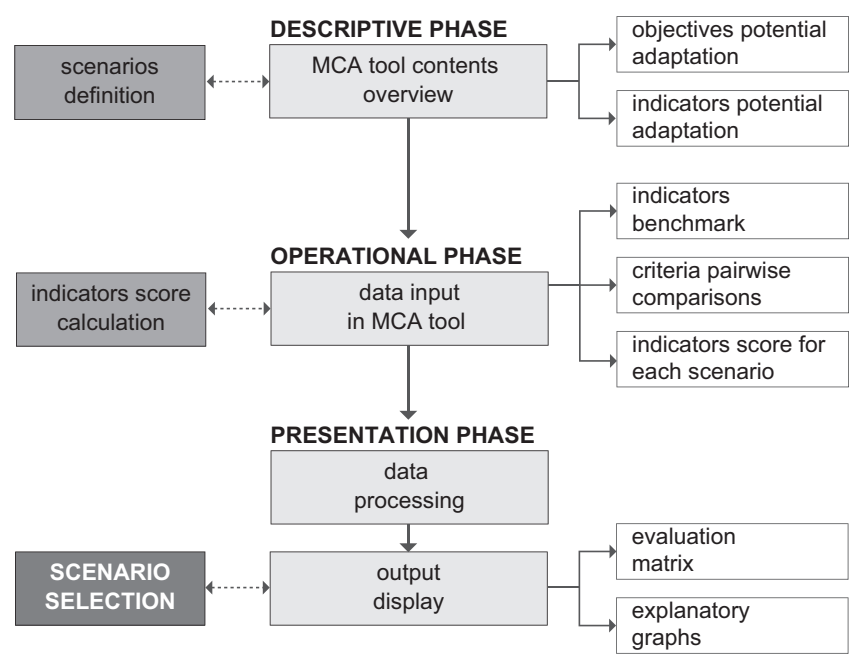

Fig. 5. Structure and operation of the proposed MCA tool.

values express the decision makers' preferences. Fictitious values also represent indicators and benchmarks that refer to common standard or to matters of judgement. The study omits elements that have a secondary importance for MCA spreadsheet operation, such as existing condition analysis. At the same time, scenario definition merely possesses an indicative character and no design ambition: the indicators' value and little more information describe each scenario, without specifying adopted planning instruments or presenting design output.

\subsubsection{Initial condition and renovation scenario presentation}

The theoretical case proposed is the renovation of a square located in Italy, in the municipality of Rome, in a medium-density area. Each edge measures $50 \mathrm{~m}$ and the square is surrounded by buildings, with an approximate height/width ratio of 0.20 . On each side of the square there is a street of $5.50 \mathrm{~m}$ width and a $2 \mathrm{~m}$ pavement; the centre of the square is used as a car park. In the initial situation, which is shown in Fig. 6, there is no equipment and no vegetation and asphalt covers the square entirely.

After a broader transport system modification, the square becomes part of a pedestrian area, with a low intensity driveway on the east side. Therefore, the municipality decides to dedicate the square to recreational activities for the neighbourhood, adding vegetation, public equipment and a playground. Within the public instrument adopted, which is not analysed in detail, the decision makers resolve to employ the proposed MCA model to support a renovation project selection. The decision makers also adapt the model to the specific situation and define benchmark values for the indicators' assessment, which correspond to the initial state or to a "business as usual" condition. Qualitative indicators have no benchmark; instead, appointed experts evaluate them directly on the normalised standard scale.

Appointed designers develop two renovation scenarios for evaluation. They also calculate quantitative indicators, except those intended for bioclimatic comfort, which are analysed separately.

Scenario A focuses on fruition and pays little attention to the rational use of resources for construction and usage. It guarantees accessibility and organises and integrates function effectively, but there is no optimisation of the lighting, waste system or water cycle and there is no renewable energy production in situ. Within scenario A (Fig. 7), the square accommodates vegetation and a small water basin; however, they respond to aesthetical criteria rather than to environmental or microclimatic guidelines. Intervention costs are slightly higher than the established budget. 
(1)
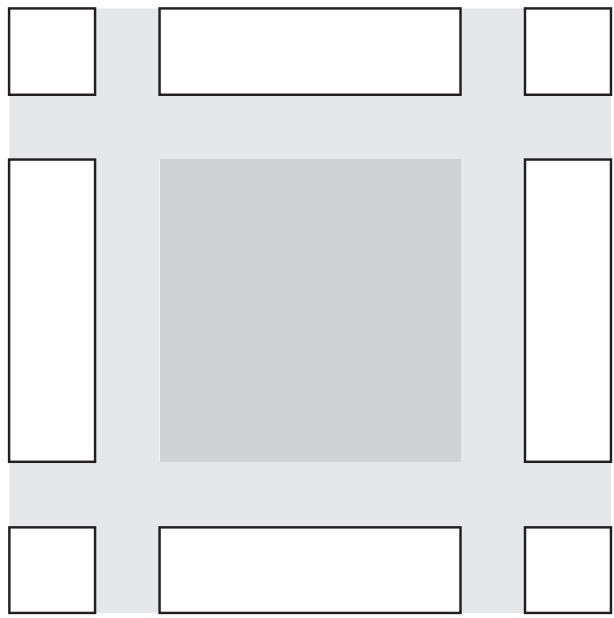

driveway with sidewalks

parking area

\section{S 1 ENVIRONMENTAL SUSTAINABILITY}

\begin{tabular}{l|l}
$\begin{array}{l}\text { I } 1.1 .1 \text { annual electrical energy consumption } \\
\text { during operation }\end{array}$ & $100 \mathrm{kWh} / \mathrm{m} 2$ year \\
\hline $\begin{array}{l}\text { I } 1.1 .2 \text { annual electrical energy demand } \\
\text { fulfilled with in-situ energy production from } \\
\text { renewable energy sources }\end{array}$ & $30 \%$ \\
\hline $\begin{array}{l}\text { I } 1.2 .1 \text { annual water consumption during } \\
\text { operation for open space maintenance }\end{array}$ & $300 \mathrm{l} / \mathrm{m} 2$ year \\
\hline $\begin{array}{l}\text { I } 1.2 .2 \text { annual non-potable water demand } \\
\text { fulfilled with in-situ storage, depuration an reuse }\end{array}$ & $30 \%$ \\
\hline $\begin{array}{l}\text { I 1.3.1 embedded energy in construction } \\
\text { materials }\end{array}$ & $13 \mathrm{MJ} / \mathrm{kg}$ \\
\hline $\begin{array}{l}\text { I } 1.3 .2 \text { reused or recycled construction } \\
\text { materials and components }\end{array}$ & $30 \%$ \\
\hline $\begin{array}{l}\text { I } 1.3 .3 \text { local construction materials and } \\
\text { components }\end{array}$ & $50 \%$ \\
\hline $\begin{array}{l}\text { I } 1.4 .1 \text { construction waste reused or recycle in } \\
\text { situ in respect to total waste production }\end{array}$ & $30 \%$ (total: $15 \mathrm{~kg} / \mathrm{m} 2$ ) \\
\hline
\end{tabular}

\section{S 3 ECONOMICAL SUSTAINABILITY}

1 3.1.1 Intervention budget

$150 € / \mathrm{m} 2$

Fig. 6. Presentation of initial conditions for the theoretical case.

Scenario B rather centres on resource consumption reduction for construction and usage. Electrical systems are optimised; native vegetation and specific gardening techniques limit irrigation; equipment and materials possess low embodied energy and they are locally produced and recycled for the most part. As in scenario A, there is no renewable energy production in situ. Rainwater is partly collected, purified and used for non-potable purposes. Within scenario B (Fig. 8), the square performs sufficiently well in terms of fruition and accessibility.

\subsubsection{MCA tool application to the theoretical case}

Weighting represents the first operational phase of the MCA model spreadsheet. This process highlights conflicts and compromises and it should include all of the decision makers and stakeholders. In the given theoretical case, however, preferences express arbitrary values, in order to describe the MCA tool process
(1)

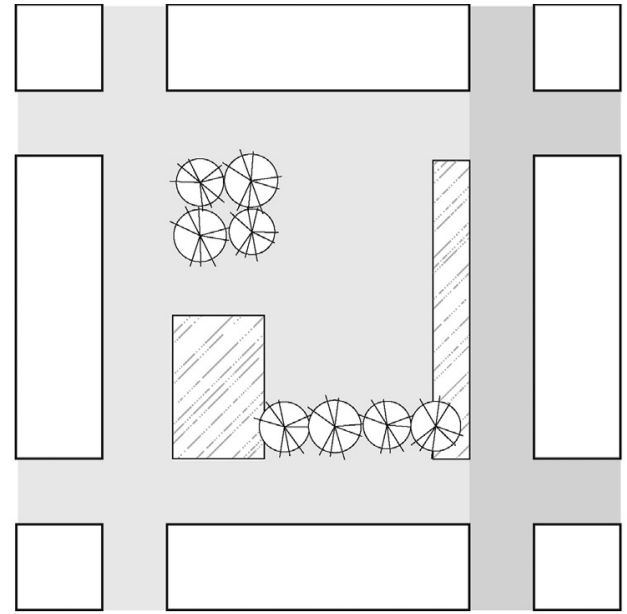

pedestrian area

driveway with sidewalks

\section{S 1 ENVIRONMENTAL SUSTAINABILITY}

\begin{tabular}{|c|c|}
\hline $\begin{array}{l}\text { I } 1.1 .1 \text { annual electrical energy consumption } \\
\text { during operation }\end{array}$ & $110 \mathrm{kWh} / \mathrm{m} 2$ year \\
\hline $\begin{array}{l}\text { I } 1.1 .2 \text { annual electrical energy demand } \\
\text { fulfilled with in-situ energy production from } \\
\text { renewable energy sources }\end{array}$ & - \\
\hline $\begin{array}{l}\text { I 1.2.1 annual water consumption during } \\
\text { operation for open space maintenance }\end{array}$ & $320 \mathrm{l} / \mathrm{m} 2$ year \\
\hline $\begin{array}{l}\text { I } 1.2 .2 \text { annual non-potable water demand } \\
\text { fulfilled with in-situ storage, depuration an reuse }\end{array}$ & $100 \mathrm{l} / \mathrm{m} 2$ year \\
\hline $\begin{array}{l}\text { I } 1.3 .1 \text { embedded energy in construction } \\
\text { materials }\end{array}$ & $15 \mathrm{MJ} / \mathrm{kg}$ \\
\hline $\begin{array}{l}1.3 .2 \text { reused or recycled construction } \\
\text { materials and components }\end{array}$ & $\begin{array}{l}10 \mathrm{~kg} / \mathrm{m} 2 \\
\text { (total: } 20 \mathrm{~kg} / \mathrm{m} 2 \text { ) }\end{array}$ \\
\hline $\begin{array}{l}\text { I } 1.3 .3 \text { local construction materials and } \\
\text { components }\end{array}$ & $\begin{array}{l}15 \mathrm{~kg} / \mathrm{m} 2 \\
\text { (total: } 20 \mathrm{~kg} / \mathrm{m} 2 \text { ) }\end{array}$ \\
\hline $\begin{array}{l}\text { I } 1.4 .1 \text { construction waste reused or recycle in } \\
\text { situ in respect to total waste production }\end{array}$ & $10 \mathrm{~kg} / \mathrm{m} 2$ \\
\hline
\end{tabular}

\section{S 3 ECONOMICAL SUSTAINABILITY}

| 3.1.1 Intervention cost

$160 € / \mathrm{m} 2$

Fig. 7. Scenario A presentation.

instead of concentrating on public consultation issues. The MCA spreadsheet has three pages for indicators, general objectives and for the weighting of specific objectives. Each page contains a priority matrix defined according to Saaty (1980), where columns and rows stand for compared elements and each cell expresses the relative preference between the correspondent column and row elements. The decision makers fill the cells with their preferences, utilising a qualitative scale; the program thus converts preferences into numbers and returns a weight for each element of the hierarchical tree, as exemplified in Fig. 9.

In the current case study, the decision makers are particularly interested in reducing water and energy consumption, in increasing bioclimatic comfort distribution throughout the area and in saving money from the initial budget. The initial page on the spreadsheet presents an overview of the weighting process. 


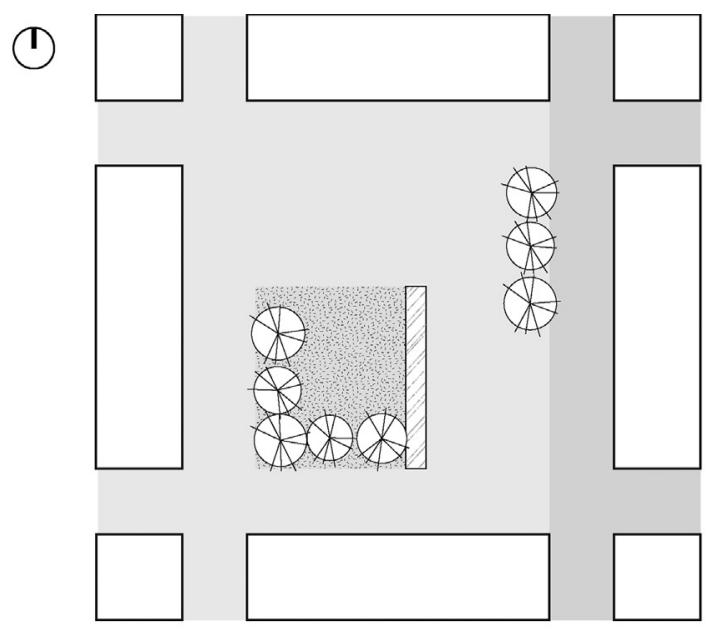

pedestrian area

driveway with sidewalks

\section{S 1 ENVIRONMENTAL SUSTAINABILITY}

I 1.1.1 annual electrical energy consumption during operation

1 1.1.2 annual electrical energy demand fulfilled with in-situ energy production from renewable energy sources

I 1.2.1 annual water consumption during operation for open space maintenance

I 1.2.2 annual non-potable water demand fulfilled with in-situ storage, depuration an reuse

I 1.3.1 embedded energy in construction materials

| 1.3.2 reused or recycled construction materials and components

I 1.3.3 local construction materials and components

I 1.4.1 construction waste reused or recycle in situ in respect to total waste production

\section{S 3 ECONOMICAL SUSTAINABILITY}

| 3.1.1 Intervention cost

$130 € / m 2$

Fig. 8. Scenario B presentation.

The study omits the evaluation of qualitative indicators. An appointed expert should measure the bioclimatic comfort indicator for existing conditions, scenario A and scenario B.

On the indicator assessment sheet, the decision makers or appointed experts insert benchmarks and non-normalised indicator values for scenario A and scenario B. The program normalises and partially aggregates the values, following Cobb-Douglas function (Cobb \& Douglas, 1928), according to weighting. In this manner, the evaluation of the scenarios reflects the decision makers' opinions, providing consistent information to enable a decision to be made. The program displays this information in a performance matrix (Fig. 10) with aggregated and non-aggregated values. In the present case, the matrix shows that Scenario A demonstrates a better performance for social sustainability, while scenario B demonstrates higher results for environmental and economic sustainability.
0.1.1. Minimize energy consumption during operation

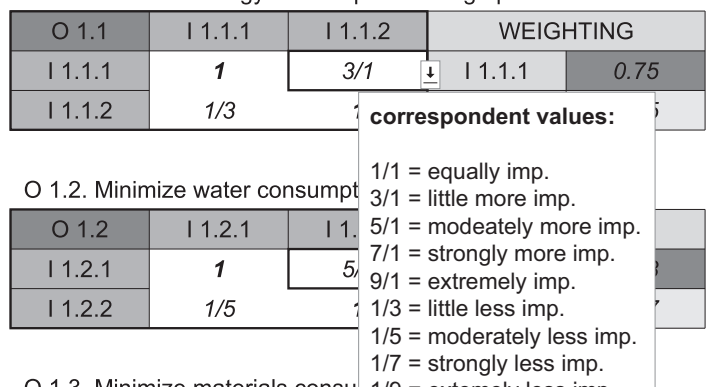

O 1.3. Minimize materials consu $1 / 9=$ extemely less imp.

\begin{tabular}{|c|c|c|c|c|c|}
\hline O 1.3 & | 1.3.1 & | 1.3.2 & I 1.3.3 & \multicolumn{2}{|c|}{ WEIGHTING } \\
\hline | 1.3 .1 & 1 & $1 / 3$ & $1 / 7$ & | 1.1.1 & 0.08 \\
\hline | 1.3.2 & $3 / 1$ & 1 & $1 / 5$ & | 1.1.2 & 0.19 \\
\hline | 1.3 .3 & $7 / 1$ & $5 / 1$ & 1 & | 1.1.3 & 0.73 \\
\hline & & & & COERENCE & verified \\
\hline
\end{tabular}

O.1.1. Minimize energy consumption during operation

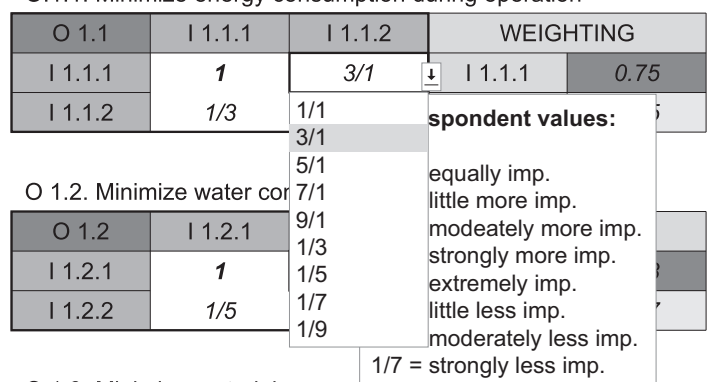

O 1.3. Minimize materials consu

\begin{tabular}{|c|c|c|c|c|c|}
\hline 01.3 & $\mid 1.3 .1$ & $\mid 1.3 .2$ & $\mid 1.3 .3$ & \multicolumn{2}{|c|}{ WEIGHTING } \\
\cline { 1 - 5 } $\mid 1.3 .1$ & $\mathbf{1}$ & $1 / 3$ & $1 / 7$ & $\mid 1.1 .1$ & 0.08 \\
\cline { 1 - 3 } $\mid 1.3 .2$ & $3 / 1$ & $\mathbf{1}$ & $1 / 5$ & $\mid 1.1 .2$ & 0.19 \\
\cline { 1 - 3 } $\mid 1.3 .3$ & $7 / 1$ & $5 / 1$ & $\mathbf{1}$ & $\mid 1.1 .3$ & 0.73 \\
\hline
\end{tabular}

Fig. 9. MCA tool weighting phase.

\begin{tabular}{|c|c|c|}
\hline & SCENARIO A & SCENARIO B \\
\hline O 1.1 & 0.73 & 1.36 \\
\hline O 1.2 & 1.02 & 1.31 \\
\hline O 1.3 & 1.20 & 0.94 \\
\hline O 1.4 & 0.53 & 0.80 \\
\hline $\begin{array}{l}\text { S } 1 \text { ENVIRONMENTAL } \\
\text { SUSTAINABILITY }\end{array}$ & 0.85 & 1.20 \\
\hline O 2.1 & 1.75 & 1.20 \\
\hline O 2.2 & 1.26 & 1.32 \\
\hline $\begin{array}{r}\text { S } 2 \text { SOCIAL } \\
\text { SUSTAINABILITY }\end{array}$ & 1.37 & 1,29 \\
\hline O 3.1 & 0.94 & 1.1 .5 \\
\hline O 3.2 & 1.10 & 1.40 \\
\hline $\begin{array}{l}\text { S } 3 \text { ECONOMICAL } \\
\text { SUSTAINABILITY }\end{array}$ & 0.96 & 1.18 \\
\hline $\begin{array}{c}\text { TOTAL } \\
\text { AGGREGATION }\end{array}$ & 1.04 & 1.17 \\
\hline
\end{tabular}

Fig. 10. Evaluation matrix comparison scenario A and scenario B performance against the weighted criteria. 
1.60

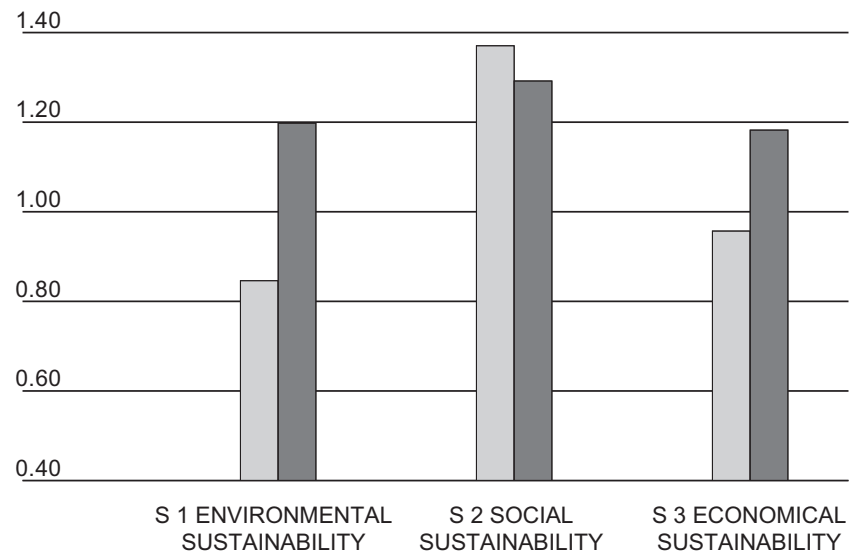

2.00

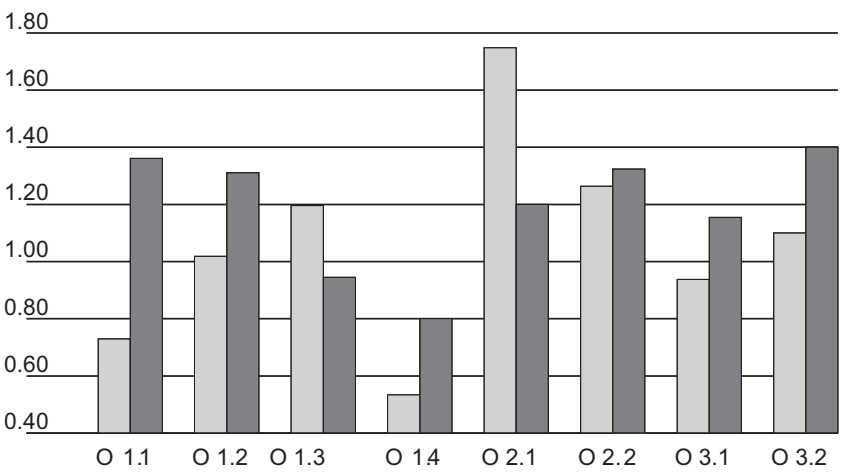

Scenario A

Scenario B

Fig. 11. Graphic representation of results using bar graphs.

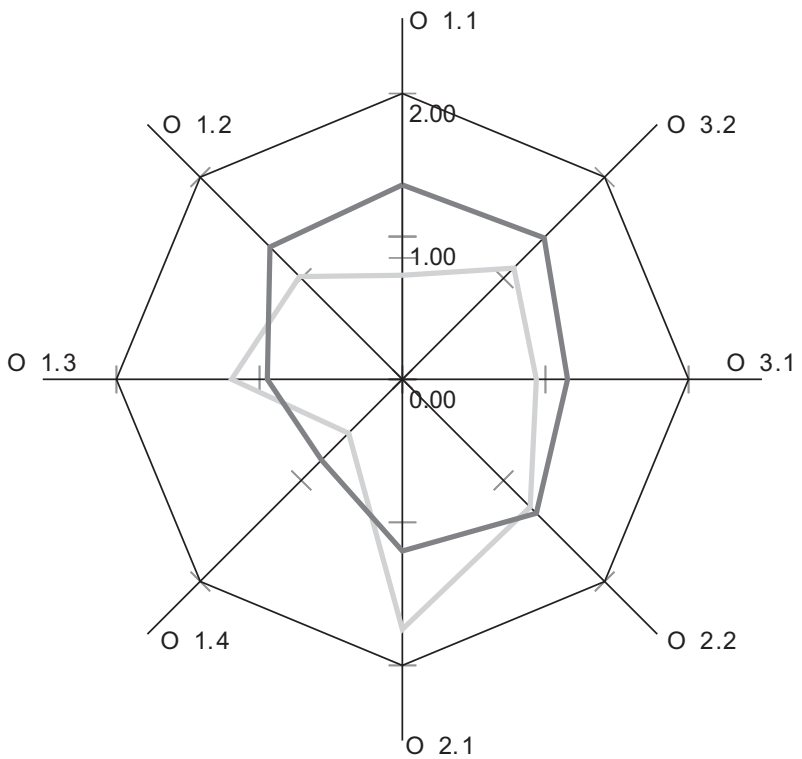

Scenario A Scenario B

Fig. 12. Graphic representation of results using radar chart.
In order to investigate the potential of the MCA model, the study also operates a total aggregation, where scenario $B$ results as the most desirable. Bar graphs (Fig. 11) and the radar chart display the same results in a more comprehensible way. The radar chart (Fig. 12) is particularly useful to compare scenarios against several variables. In the case study, the scenario B radar chart displays a more homogenous distribution of evaluation results for different aspects. On the other hand, scenario B generally demonstrates a poorer performance for every indicator, except fruition and material consumption, represented by two peaks for the correspondent values.

As stated above on several occasions, results can provide room for discussion and clarify the situation, but they do not provide an answer; the decision makers can consider results or discard them, according to their own personal judgement.

\section{Discussion and conclusion}

As part of the European strategy for sustainable urban regeneration, open space renovation can contribute significantly to promote the environmental compatibility of cities and the quality of life of their inhabitants. A holistic approach to open space renovation requires decision support techniques that take into account multiple, correlated parameters/factors and heterogeneous stakeholders. In order to address this demand, the study has developed a multicriteria analysis tool (MCA) for open spaces, enhancing existing MCA methods for a definite open space typology.

Following the example of environmental certificates, which refer to a comparable scale and planning stage, the proposed tool is partially set up, providing a list of objectives and correspondent assessment indicators in a hierarchical structure. Still, along with MCA models for strategic urban policy, it highlights the decision makers' specific targets and trade-offs towards the current situation, by defining the indicators' benchmarks and criteria's weights locally (Schärlig, 1985).

This distinct approach to MCA has proved positively suitable for the decision process of public open space renovations, as it provides a directly operable support tool, which can be customised according to the actual requirements of the conditions in different spaces. The tool is indeed easy to understand and apply and it ensures a robust comparison between qualitative and quantitative issues in a standard numerical scale. The algorithm selected in this study is very effective for assisting complex requirements on a medium intervention scale, focusing on the performance evaluation of existing and future scenarios. The data module has been developed to comprehend a significant set of properties in open space, but it is flexible to be adjusted or enriched according to the demands of public bodies. Future efforts are expected to promote the tool's application and to extend its use to several types and sizes of public open spaces in cities.

\section{References}

Adriaanse, A. (1993). Environmental policy performance indicators: A study on the development of indicators for environmental policy in the Netherlands. Netherlands: Sdu Uitgeverij Konintginnegracht.

Alexander, C., Ishikawa, S., \& Silverstein, M. (1977). A pattern language: Towns, buildings, construction. New York: Oxford University Press.

Bell, M. L., Hobbs, B. F., Elliott, E. M., Ellis, H., \& Robinson, Z. (2001). An evaluation of multi-criteria methods in integrated assessment of climate policy. Journal of Multi-Criteria Decision Analysis, 10(5), 229-256. http://dx.doi.org/10.1002/ mcda.305

Böhner, C. (2006). Decision-support systems for sustainable urban planning. International Journal of Environmental Technology and Management, 6(1), 193-205.

Carmona, M. (2010). Contemporary public space: Critique and classification. Journal of Urban Design, 15(1), 123-148. http://dx.doi.org/10.1080/ 13574800903435651

Carmona, M., \& Tiesdell, S. (2007). Urban design reader. Burlington: Elsevier. 
Centre for Renewable Energy Sources (Pikermi), Department of Buildings. (2004). Designing open spaces in the urban environment: A bioclimatic approach. Athens: Centre for Renewable Energy Sources.

Choo, E. U., Schoner, B., \& Wedley, W. C. (1999). Interpretation of criteria weights in multicriteria decision making. Computers \& Industrial Engineering, 37(3), 527-541. http://dx.doi.org/10.1016/S0360-8352(00)00019-X

Chrysoulakis, N. (2008). Urban metabolism and resource optimisation in the urban fabric: The BRIDGE methodology. Proceedings of EnviroInfo 2008: environmental informatics and industrial ecology (Vol. 12) Shaker Verlag: Leuphana University of Lüneburg.

Cliímaco, J. (1997). Multicriteria analysis. New York: Springer-Verlag.

Cobb, C. W., \& Douglas, P. H. (1928). A theory of production. American Economic Review, 18(1), 139-165.

Commission for Architecture and the Built Environment, \& Greater London Authority. (2008). Open space strategy: Best practice guidance: A joint consultation draft by the Mayor of London and CABE Space. London: Greater London Authority Press.

Curwell, S.(Ed.).(2005a). Sustainable urban development, the framework and protocols for environmental assessment (Vol. 1). London: Taylor \& Francis.

Curwell, S. (Ed.). (2005b). Sustainable urban development: The environmental assessment methods (Vol. 2). London: Routledge.

Department for Communities, \& Local Government. (2009). Multi-criteria analysis: A manual. Wetherby: Communities and Local Government Publications.

Department of the Environment, Transport and the Regions, \& Commission for Architecture and the Built Environment. (2000). By design: Urban design in the planning system: Towards better practice. London: Department of the Environment, Transport and the Regions.

Donnelly, A., Jones, M., O’Mahony, T., \& Byrne, G. (2007). Selecting environmental indicator for use in strategic environmental assessment. Environmental Impact Assessment Review, 27(2), 161-175. http://dx.doi.org/10.1016/j.eiar.2006.10.006

European Commission. (1991). Green paper on the urban environment. Bruxelles.

European Commission. (1999). Towards environmental pressure indicators for the EU. Luxembourg: Office for Official Publications of the European Communities.

European Environment Agency (EEA). (2005a). EEA core set of indicators: Guide. Luxembourg: European Environment Agency.

European Environment Agency (EEA). (2005b). European environment outlook. Luxembourg: Office for Official Publications of the European Communities.

European Ministers on Urban Development. (2010). Toledo informal ministerial meeting on urban development declaration. Toledo.

Fröhlich, D., \& Matzarakis, A. (2013). Modeling of changes in human thermal bioclimate resulting from changes in urban design: Example based on a popular place in Freiburg, Southwest Germany. In Advances in meteorology, climatology and atmospheric physics. Springer.

Futcher, J. A., Kershaw, T., \& Mills, G. (2013). Urban form and function as building performance parameters. Building and Environment, $62 \mathrm{http}: / / \mathrm{dx}$. doi.org/10.1016/j.buildenv.2013.01.021

Gabrielsen, P., \& Bosch, P. (2003). Environmental indicators: Typology and use in reporting. European Environment Agency. EEA internal working paper.

Gehl, J. (1980). Life between buildings: Using public space. New York: Van Nostrand Reinhold.

GFA Consulting. (1996). Greening the city: A guide to good practice. Norwich: H.M.S.O.

Gibson, R. (2005). Sustainability assessment: Criteria and processes. London: Earthscan.

Givoni, B. (1998). Climate considerations in building and urban design. New York: Van Nostrand Reinhold.

González, A., Donnelly, A., Jones, M., Chrysoulakis, N., \& Lopes, M. (2013). A decision-support system for sustainable urban metabolism in Europe. Environmental Impact Assessment Review, 38, 109-119. http://dx.doi.org/10.1016/ j.eiar. 2012.06.007

Goodwin, P., \& Wright, G. (1991). Decision analysis for management judgment. Chichester: Wiley.

Great Britain, \& Treasury. (2003). The green book: Appraisal and evaluation in central government: Treasury guidance. London: TSO.

Greening, L. A., \& Bernow, S. (2004). Design of coordinated energy and environmental policies: Use of multi-criteria decision-making. Energy Policy, 32(6), 721-735. http://dx.doi.org/10.1016/j.enpol.2003.08.017

Hewitt, N. (1995). European Local Agenda 21 Planning Guide: How to engage in longterm environmental action planning towards sustainability? Bruxelles: European Sustainable Cities \& Towns Campaign.

Hobbs, B. F., \& Meier, P. (2000). Energy decisions and the environment: A guide to the use of multicriteria methods. Boston, MA: Springer US.
Homes, \& Community Agency. (2000). Urban design compendium. London: LlevelynDavies.

Höppe, P. (1993). Heat balance modelling. Cellular and Molecular Life Sciences, 49(9), 741-746. http://dx.doi.org/10.1007/BF01923542

Hwang, C.-L., \& Yoon, K. (1981). Multiple attribute decision making: Methods and applications. Berlin: Springer-Verlag.

Keeney, R. L. (1982). Decision analysis: An overview. Operations Research, 30(5), 803-838. http://dx.doi.org/10.1287/opre.30.5.803

Kottek, M., Grieser, J., Beck, C., Rudolf, B., \& Rubel, F. (2006). World Map of the Köppen-Geiger climate classification updated. Meteorologische Zeitschrift, 15(3) 259-263. http://dx.doi.org/10.1127/0941-2948/2006/0130

Lee, W. L. (2012). Benchmarking energy use of building environmental assessment schemes. Energy and Buildings, 45, 326-334. http://dx.doi.org/ 10.1016/j.enbuild.2011.11.024

Lehtonen, M. (2004). The environmental-social interface of sustainable development: Capabilities, social capital, institutions. Ecological Economics, 49(2), 199-214. http://dx.doi.org/10.1016/j.ecolecon.2004.03.019

Lofland, L. H.(1998). The public realm: Exploring the city's quintessential social territory New York: Aldine de Gruyter.

Makropoulos, C. K., Natsis, K., Liu, S., Mittas, K., \& Butler, D. (2008). Decision support for sustainable option selection in integrated urban water management. Environmental Modelling E'Software,23(12), 1448-1460. http://dx.doi.org/ 10.1016/j.envsoft.2008.04.010

Matthies, M., Giupponi, C., \& Ostendorf, B. (2007). Environmental decision support systems: Current issues, methods and tools. Environmental Modelling E'Software 22(2), 123-127. http://dx.doi.org/10.1016/j.envsoft.2005.09.005

Matzarakis, A., Mayer, H., \& Iziomon, M. G. (1999). Applications of a universal therma index: Physiological equivalent temperature. International Journal of Biometeorology, 43(2), 76-84. http://dx.doi.org/10.1007/s004840050119

Montibeller, G., Gummer, H., \& Tumidei, D. (2006). Combining scenario planning and multi-criteria decision analysis in practice. Journal of Multi-Criteria Decision Analysis, 14(1-3), 5-20. http://dx.doi.org/10.1002/mcda.403

Morrison-Saunders, A., \& Therivel, R. (2006). Sustainability integration and assessment. Journal of Environmental Assessment Policy and Management, 08(03) 281-298. http://dx.doi.org/10.1142/S1464333206002529

Newman, P., \& Kenworthy, J. (1999). Sustainability and cities: Overcoming automobile dependence. Washington: Island Press.

Niemczynowicz, J. (1999). Urban hydrology and water management - Present and future challenges. Urban Water, 1(1), 1-14. http://dx.doi.org/10.1016/S14620758(99)00009-6

Organisation for Economic Co-operation and Development (OECD). (1993). OECD core set of indicators for environmental performance reviews. Paris: OECD Environment Directorate.

Organisation for Economic Co-operation and Development (OECD). (2003). OECD environmental indicators: Development measurement and use. Paris: OECD Environment Directorate.

Pohekar, S. D., \& Ramachandran, M. (2004). Application of multi-criteria decision making to sustainable energy planning-A review. Renewable and Sustainable Energy Reviews, 8(4), 365-381. http://dx.doi.org/10.1016/j.rser.2003.12.007

Roseland, M. (2000). Sustainable community development: Integrating environmental, economic, and social objectives. Progress in Planning, 54(2), 73-132. http://dx.doi.org/10.1016/S0305-9006(00)00003-9

Rykwert, J. (2000). The seduction of place: The history and future of the city. Oxford: Oxford University Press.

Saaty, T. L. (1980). The analytic hierarchy process: Planning, priority setting, resource allocation. New York: McGraw-Hill.

Schärlig, A. (1985). Décider sur plusieurs critères: panorama de l'aide à la décision multicritère. Lausanne: Presses polytechniques romandes.

Sennett, R. (1977). The fall of public man. New York: Knopf.

Steuer, R. E. (1986). Multiple criteria optimization: Theory, computation, and application. New York: Wiley.

Stewart, T. J., French, S., \& Rios, J. (2013). Integrating multicriteria decision analysis and scenario planning-Review and extension. Omega, 41(4), 679-688. http://dx.doi.org/10.1016/j.omega.2012.09.003

Tibbalds, F. (1992). Making people-friendly towns: Improving the public environment in towns and cities. Harlow: Longman.

Tzeng, G.-H., \& Huang, J.-J. (2011). Multiple attribute decision making: Methods and applications. CRC Press.

Voogd, H. (1983). Multicriteria evaluation for urban and regional planning. London: Pion.

Whyte, W. H. (1980). The social life of small urban spaces. New York: Project for Public Spaces. 